\title{
Article
}

\section{Torta da polpa de macaúba na dieta de cabras leiteiras}

\author{
Erica Beatriz Schultz ${ }^{*}$, Samuel de Melo Goulart ${ }^{1}$, Ingrid Soares Garcia ${ }^{1}$, \\ Rafael Marzall do Amaral ${ }^{2}$, Jose Antonio Saraiva Grossi ${ }^{1}$
}

\begin{abstract}
RESUMO
Para avaliar o desempenho e a viabilidade econômica da inclusão da torta da polpa de macaúba na dieta de cabras em lactação, 16 animais adultos foram separados em duas baias coletivas contendo oito animais cada, com uma das baias recebendo concentrado contendo $41,2 \mathrm{~g} \cdot \mathrm{kg}^{-1} \mathrm{de}$ torta da polpa de macaúba. A adição da torta ao concentrado reduziu o consumo de volumoso sem afetar o desempenho dos animais. Da mesma forma, o teor de proteína, gordura, lactose e sólidos totais do leite não foi afetado. O custo com alimentação foi reduzido com a inclusão da torta à dieta dos animais. A inclusão da torta da polpa de macaúba à dieta de cabras em lactação mostrou-se técnica e economicamente viável para o nível de inclusão avaliado.

Palavras-chave: Acrocomia aculeata, caprinos, subproduto, ração, ruminantes.
\end{abstract}

\section{Introdução}

Vários alimentos destinados à suplementação animal competem na cadeia da alimentação humana, tornando seu custo elevado e limitando a rentabilidade dos sistemas de produção. As despesas com o manejo nutricional de caprinos no sistema de criação intensivo são superiores a 60 \%, sendo, o principal componente do custo de produção pecuário (LOPES \& FERREIRA, 2017).

Por essa razão, cada vez mais alimentos alternativos que possam substituir total ou parcialmente os tradicionais, especialmente para

\footnotetext{
${ }^{1}$ Departamento de Zootecnia, Universidade Federal de Viçosa, Viçosa 36570, Minas Gerais, Brasil.

2 EARTH University, San José 4442-1000, Costa Rica.

* Corresponding author: Av. P H Rolfs, s/nº, Campus Universitário, Viçosa - MG, Cep 36570-900 (31) 36124620. E-mail: ericabeatrizschultz@gmail.com
} 
ruminantes, são avaliados. Subprodutos do processamento de frutas, farelo de cacau, casca de café, entre outros, foram estudados como opção para essa substituição (VASCONCELOS et al., 2002; PIRES et al., 2015). Porém a viabilidade econômica para a utilização desses subprodutos depende, primariamente, de sua disponibilidade regional e também do seu valor nutritivo.

A macaúba [Acrocomia aculeata (Jacq.) Lodd. ex Martius] é uma palmeira nativa das regiões tropicais das Américas e já foi considerada a de maior dispersão na América latina (HENDERSON et al., 1997) e também no Brasil (RATTER et al., 2003), podendo ser cultivada em praticamente todo o território brasileiro, haja vista sua adaptabilidade a várias condições ambientais (PIRES et al., 2013).

Os óleos extraídos da polpa e amêndoa da macaúba despertam interesse cada vez maior de indústrias químicas, farmacêuticas e alimentícias, fazendo com que nos últimos anos várias iniciativas, nacionais e estrangeiras invistam no plantio comercial da macaúba no estado de Minas Gerais com vistas à produção de óleo vegetal (COLOMBO et al., 2017).

O modelo de exploração que se desenha para a macaúba implica a geração de volume considerável de resíduos. De acordo com Evaristo et al. (2017), a polpa corresponde a quase 50 \% da massa do fruto. Após a extração do óleo, a torta da polpa constitui um dos principais resíduos gerados no processamento dos frutos de macaúba (ALTINO et al.,2017).

Trabalhos recentes têm demonstrado o uso potencial da torta da polpa da macaúba na alimentação de ruminantes (AZEVEDO et al., 2012; AZEVEDO et al., 2013; RIGUEIRA et al., 2017), com cerca de $8 \%$ de proteína bruta, similar ao milho, principal alimento energético utilizado em dietas, e $14 \%$ de extrato etéreo, demonstrando ser uma boa fonte de energia para os animais. Além disso, a ausência de fatores antinutricionais, geralmente encontrados em tortas ou farelos obtidos de outras fontes 
oleaginosas, como a soja, o amendoim, e o girassol, entre outras, permite a utilização direta da torta da macaúba na alimentação animal, sem custos adicionais com processos de detoxificação (GRANDE \& CREN, 2016).

Portanto, a proposta deste estudo foi avaliar a viabilidade técnica e econômica da utilização da torta da polpa de macaúba na dieta de cabras em lactação.

\section{Material e métodos}

O experimento foi realizado no setor de caprinocultura da Universidade Federal de Viçosa durante o período de 27 de janeiro a 28 fevereiro de 2018, totalizando 30 dias. Foram utilizadas 16 cabras adultas pardas alpinas em torno de $120 \pm 15$ dias de lactação, com massa corporal média de 57,3 $\pm 2,0 \mathrm{~kg}$ e produção média de leite de $2,8 \pm 0,200 \mathrm{~kg}^{-\mathrm{d}^{-}}{ }^{-1}$.

As dietas experimentais foram compostas por $41 \%$ de silagem de milho e $59 \%$ de concentrado formulado de acordo os requerimentos nutricionais propostos no National Research Council (2007). O concentrado do tratamento controle foi formulado com milho e farelo de soja, e o tratamento com macaúba formulado com $4,12 \%$ de torta da polpa de macaúba, milho e farelo de soja, mantendo as dietas com mesmo perfil químico (Tabela 1).

Tabela 1. Composição percentual e química das dietas.

\begin{tabular}{ccc}
\hline Alimento & Concentrado $\left(\mathrm{g} \cdot \mathrm{kg}^{-1}\right)$ & $\begin{array}{c}\text { Concentrado com macaúba } \\
\left(\mathrm{g} \cdot \mathrm{kg}^{-1}\right)\end{array}$ \\
\hline Silagem de milho & 416,7 & 411,9 \\
Farelo de soja & 166,7 & 156,5 \\
Farelo de milho & 416,7 & 390,4 \\
Torta da polpa de macaúba & - & 41,2 \\
\hline Composição na matéria seca & Concentrado $\left(\mathrm{g} \cdot \mathrm{kg}^{-1}\right)$ & Concentrado com macaúba \\
& & $\left(\mathrm{g} \cdot \mathrm{kg}^{-1}\right)$ \\
\hline Proteína bruta & 148 & 144 \\
Fibra em detergente neutro & 301 & 311 \\
Extrato etéreo & 38 & 42 \\
Matéria mineral & 34 & 33 \\
Carboidrato não estrutural & 490 & 482 \\
\hline
\end{tabular}


A torta de macaúba foi obtida após extração do óleo da polpa feita por prensagem a frio, sendo em seguida processada em moedor a fim de reduzir a granulometria e permitir sua mistura aos demais componentes da ração. As análises químicas e bromatológicas de matéria seca, proteína bruta, matéria mineral, fibra em detergente neutro e extrato etéreo das dietas e da torta da polpa da macaúba se realizaram de acordo com Detmann et al. (2012) ( Tabela 1) (Tabela 2).

Tabela 2. Composição química da torta da polpa de macaúba

\begin{tabular}{cc}
\hline Composição química & Torta de polpa de macaúba (g.kg-1) \\
\hline Matéria seca & 869 \\
Proteína bruta & 95 \\
Fibra em detergente neutro & 420 \\
Extrato etéreo & 95 \\
\hline
\end{tabular}

Os animais foram alojados em baias coletivas, sendo oito animais por baia. As baias eram cobertas por cama de serragem, com água e mistura mineral ofertados ad libitum. Previamente à tomada de dados, os animais passaram por um período de adaptação à dieta que durou sete dias. A silagem foi ofertada duas vezes ao dia às $7 \mathrm{~h}$ e $15 \mathrm{~h}$, sempre após a ordenha, e o concentrado ofertado quatro vezes ao dia: às $7 \mathrm{~h}$, às $12 \mathrm{~h}$, às $15 \mathrm{~h}$ e às $17 \mathrm{~h}$. $\mathrm{O}$ consumo foi contabilizado diariamente após o período de adaptação, considerando-se a diferença entre o alimento ofertado e as sobras.

A produção leiteira foi mensurada uma vez por semana às $6 \mathrm{~h}$ e às 14 $\mathrm{h}$ através de medidores na ordenha mecanizada, totalizando quatro controles por animal ao longo do período experimental. Para a composição do leite, foram realizadas coletas no $15^{\circ}$ e $25^{\circ}$ dia de experimento em potes apropriados contendendo Bronopol $^{\circledR}$ (2-bromo-2-nitropropane-1,3-diol). As alíquotas foram representativas das duas ordenhas, sendo feitas leituras através do equipamento MilkoScan ${ }^{\mathrm{TM}}$ Minor (Foss, Dinamarca) para determinar a porcentagem de gordura, proteína, lactose e sólidos totais. Para controle da variação da massa corporal e ganho médio diário, os 
animais foram pesados no $1^{\circ}, 8^{\circ}, 15^{\circ}$ e $27^{\circ}$ dia de experimento, após a ordenha e antes da primeira oferta de alimento do dia. A análise econômica da alimentação foi avaliada segundo metodologia proposta por Rennó et al. (2008): custo total da silagem (multiplicação da quantidade de volumoso pelo seu valor de mercado), custo total de concentrado (multiplicação das quantidades de cada ingrediente que compunha o concentrado das dietas pelo seu respectivo valor de mercado) com base no preço da silagem de milho, do farelo de soja e do farelo de milho do mercado; e para a torta da macaúba o preço estimado por Azevedo et al. (2013), de R\$ 0,32.kg-1. Por fim, foi feito o custo por animal por dia (somatório do custo do concentrado e do custo do volumoso).

As análises estatísticas foram realizadas segundo o modelo: $Y=\mu+T_{i}+e_{i j}$, em que $\mathrm{Y}$ é a variável reposta; $\mu$ é uma constante; $\mathrm{T}$ é o efeito do uso de concentrado com e sem a torta da polpa de macaúba; e e é o erro aleatório. Para a comparação das médias, foi utilizado o teste t-Student a $5 \%$ de significância para a ocorrência do erro tipo I. Para as variáveis de consumo e econômica, foram realizadas análises descritivas.

\section{Resultados e discussão}

Com a dieta contendo a torta da polpa de macaúba no concentrado, foi observada uma redução de 28,73 \% no consumo de silagem em relação aos animais alimentados somente com farelo milho e soja (Tabela 3). Não houve sobras de concentrado em ambos os tratamentos, demonstrando que ao nível de inclusão de 4,12 \% a torta da polpa da macaúba não é rejeitada pelas cabras. Essa observação é de suma importância, pois a cabra é classificada como seletiva intermediária, sendo mais sensitiva a mudanças na composição da dieta que os demais ruminantes domésticos, como a vaca e a ovelha (HOFMANN, 1989), fato confirmado por Morand-Fehr et al. (2007) 
em testes de cafeteria, onde os caprinos foram capazes de rejeitar alimentos com nível de inclusão de $0,12 \%$ na dieta total.

Tabela 3. Produção e ganho médio diário de cabras alimentadas ou não com a torta de macaúba no concentrado

\begin{tabular}{cccc}
\hline \multirow{2}{*}{ Variáveis } & \multicolumn{2}{c}{ Tratamentos } & \multirow{2}{*}{$\begin{array}{c}\text { Concentrado com } \\
\text { macaúba }\end{array}$} \\
\cline { 2 - 3 } & Concentrado & 2,868 & 0,9917 \\
\hline Produção de leite (kg) & 2,867 & 1,9 & $*$ \\
Consumo de silagem (kg. dia-1 MN) & 2,68 & 1,5 & $*$ \\
Consumo de concentrado (kg. dia $\left.{ }^{-1} \mathrm{MN}\right)$ & 1,5 & 0,122 & 0,6860 \\
Ganho médio diário $(\mathrm{kg})$ & 0,110 & &
\end{tabular}

* Análise descritiva. MN: matéria natural.

A redução do consumo de volumoso pode ser atribuída à concentração de extrato etéreo do subproduto, porque a torta da polpa de macaúba apresentou em média $12 \%$.Os lipídios possuem alto valor calórico, cerca de 2,25 vezes maior que os carboidratos. Quando alimentos com teores consideráveis de óleo são adicionados à ração, há um adensamento energético da dieta e uma redução no volume ingerido para suprir a demanda do animal (PALMQUIST \& JENKINS,1980).

Não houve diferença no desempenho produtivo $(p>0,05)$ de cabras que receberam o concentrado contendo torta de macaúba, em comparação àquelas que receberam concentrado contendo somente milho e soja (Tabela 3).

A manutenção dos níveis de produção ao longo da lactação envolve diversas adaptações fisiológicas pela demanda nutricional, sendo necessária a oferta adequada de nutrientes. $\mathrm{O}$ aumento na ingestão de alimentos ocorre após o pico de produção. Nesse período, é possível atingir o equilíbrio entre a demanda e o aporte de nutrientes e estabelecer o balanço energético positivo (BAUMAN, 2000). As cabras apresentaram ganho de massa corporal, uma vez que o período experimental ocorreu após o pico de lactação. As dietas consumidas permaneceram em equilíbrio entre si e proporcionaram a mesma média de produção de leite e ganho médio diário (Tabela 3). 
O desempenho na lactação é dependente do aporte de nutrientes. $\mathrm{O}$ teor de lipídeos na torta da polpa da macaúba é um aspecto benéfico no fornecimento de energia e mantença no nível de produção em comparação a concentrados contendo somente milho e soja (Tabela 3). Para vacas leiteiras, a adição de 3,0 a 6,9 \% de lipídios na matéria seca aumentou a eficiência de utilização da energia (CHILLIARD, 1993). A mudança no aproveitamento da energia está ligada à ação antiprotozoário dos lipídeos, haja vista que protozoários são responsáveis por até $37 \%$ do gasto energético através da metanogênese, fato confirmado por Santos et al. (2017), que, ao fornecer o subproduto da polpa de macaúba em níveis acima de 100 g.kg-1 de matéria seca, encontraram redução na população de protozoários.

A inserção de alimentos com considerável teor de lipídeos na dieta de ruminantes requer, entretanto, alguns cuidados; o excesso de gordura reduz a digestibilidade da fibra e a produção de gordura no leite. O nível de inclusão da torta de macaúba na ração utilizado neste trabalho (100 g.animal ${ }^{-1} \cdot$ dia $^{-1}$ ) não resultou em prejuízos produtivos, visto que o teor de extrato etéreo na matéria seca se enquadra dentro do limite de 5 a $7 \%$ estabelecido por Palmquist \& Jenkins (1980).

Apesar da elevada porcentagem de fibras na torta da polpa da macaúba, este não foi um fator limitante ao desempenho, possivelmente devido à quantidade fornecida e ao processamento físico do subproduto até granulometria semelhante à dos alimentos concentrados padrão (Tabela 3). Em um estudo com a torta da polpa de macaúba ofertada a ovinos, o consumo não foi alterado com o aumento na inclusão da torta na dieta, possivelmente em razão do processamento desta, que reduziu o tamanho da partícula da fibra, favorecendo o trânsito pelo trato digestório sem efeito de repleção ruminal (SANTOS et al., 2017).

Segundo Queiroga et al. (2009), uma vez que a passagem da digesta pelo rúmen é mais rápida em cabras que em vacas, efeitos negativos de uma dieta rica em óleos na digestão ruminal de fibras são menores em cabras. 
Esse fato, tomado isoladamente, permite supor que maiores níveis de inclusão da torta da polpa de macaúba, alimento rico em óleo, seriam possíveis para cabras em lactação, sem prejuízo na produção de leite.

Durante o período de lactação, alterações de lote ou nível energético das dietas podem ocasionar mudanças na produção e composição do leite após dois a quatro dias (RISCO \& MELENDEZ, 2011). Não foi observada diferença para composição do leite de cabras alimentadas ou não com a torta da macaúba $(\mathrm{p}<0,05)$ (Tabela 4).

Tabela 4. Composição do leite de cabras alimentadas com e sem torta de macaúba na dieta

\begin{tabular}{|c|c|c|c|}
\hline \multirow[b]{2}{*}{ Variáveis } & \multicolumn{2}{|c|}{ Tratamentos } & \multirow[b]{2}{*}{ p-valor } \\
\hline & Concentrado & $\begin{array}{c}\text { Concentrado com } \\
\text { macaúba }\end{array}$ & \\
\hline Proteína (g.animal ${ }^{-1} \cdot$ dia $^{-1}$ ) & 84,30 & 82,46 & 0,7839 \\
\hline Gordura (g.animal ${ }^{-1} \cdot$ dia $^{-1}$ ) & 108,18 & 100,02 & 0,3356 \\
\hline Lactose (g.animal-1. dia $^{-1}$ ) & 128,80 & 126,36 & 0,7814 \\
\hline Sólidos totais (g.animal ${ }^{-1} \cdot$ dia $^{-1}$ ) & 349,32 & 336,32 & 0,5865 \\
\hline
\end{tabular}

De acordo com Chilliard et al. (2007), cabras em lactação apresentam boa tolerância à adição de gorduras insaturadas à dieta. Sendo assim, a torta da polpa de macaúba, tendo um considerável teor de extrato etéreo (Tabela 2), apresenta-se como uma boa alternativa ao sistema intensivo de produção, em que a alta produtividade deve estar aliada à manutenção de características desejáveis do leite.

A quantidade de gordura no leite não se alterou significativamente ( $p>0,05)$ com a adição da torta de macaúba (Tabela 4), possivelmente devido à pequena participação da torta no cômputo total da matéria seca ofertada (3,8 \%). Contudo, segundo Azevedo et al. (2013), uma maior inclusão da torta da macaúba na dieta de caprinos seria tecnicamente viável, podendo então promover tal alteração. Embora o perfil de ácidos graxos do leite não tenha sido avaliado neste trabalho, de acordo com Jenkins, (1998), a inclusão de óleo rico em ácido oleico (C18:1) na dieta dos animais leva ao 
aumento em sua proporção no perfil graxo do leite, melhorando sua qualidade nutricional.

O teor de lactose não foi alterado com a utilização da macaúba (Tabela 4). Segundo Madureira et. al.(2017), esse é o componente químico mais estável do leite, responsável pela regulação da pressão osmótica e consequentemente pela própria produção de leite. Os sólidos totais estão diretamente ligados à porcentagem de gordura, proteína e lactose, logo, como nenhum dos componentes químicos do leite apresentou diferença estatística entre os tratamentos, esperava-se que esse componente mantivesse o mesmo padrão de resposta (Tabela 4). Todos os tratamentos mantiveram os requisitos mínimos de qualidade do leite de cabra estabelecidos pela Instrução Normativa (IN) $\mathrm{n}^{\circ} 37$, quais sejam: teores mínimos de 0,6 a 2,9 \% para gordura; 2,8 \% para proteína; 4,3\% para lactose e 8,2 \% para sólidos totais (MAPA, 2000).

A inclusão da torta da polpa da macaúba promoveu a redução dos custos com alimentação sem prejuízos na produção (Tabela 5). Resultado similar foi encontrado por Azevedo et al. (2012) com a inclusão de $100 \mathrm{~g} \mathrm{~kg}^{-1}$ de torta da macaúba na ração de cordeiros. Atualmente, não há mercado para a torta da polpa de macaúba, sendo esta um passivo para a indústria de processamento de óleo. Desta forma, a torta é obtida sem custos, resultando em redução direta do custo com concentrado, que é parcialmente substituído pela torta, e em redução indireta em virtude da diminuição no consumo de silagem (Tabela 5). 
Tabela 5. Composição do custo da alimentação e margem obtida com a venda do leite por animal

\begin{tabular}{|c|c|c|}
\hline \multirow{2}{*}{ Variáveis } & \multicolumn{2}{|r|}{ Tratamentos } \\
\hline & Concentrado & Concentrado com macaúba \\
\hline Consumo de silagem (kg.dia-1) & 2,68 & 1,9 \\
\hline Consumo de concentrado (kg.dia $\left.{ }^{-1}\right)$ & 1,5 & 1,5 \\
\hline Custo da silagem $\left(\mathrm{kg}^{*}\right)$ & 0,15 & 0,15 \\
\hline Custo do concentrado (kg**) & 0,72 & 0,70 \\
\hline Custo animal ${ }^{-1}$ dia $^{-1}(\mathrm{R} \$)$ & 1,48 & 1,26 \\
\hline Preço do litro do leite $(\mathrm{R} \$) * * *$ & 1,68 & 1,68 \\
\hline Margem $(\mathrm{R} \$)$ & 0,20 & 0,42 \\
\hline
\end{tabular}

*Preço consultado no MFRURAL 20/08/2018. **Preço das commodities que compõem o concentrado, segundo Scot Consultoria 20/8/2018. Calculado considerando a proporção dos componentes apresentados na Tabela $1 .{ }^{* * *}$ Preço de referência pago pela Caprileite em 20/8/2018.

As tortas com elevado teor de gordura, além de reduzirem diretamente os custos com alimentação, auxiliam na mitigação da produção de metano entérico, um dos principais causadores do efeito estufa, podendo, no futuro, render créditos de carbono à propriedade (ABDALLA et al., 2008). Logo, é de grande contribuição o estudo de alimentos alternativos como a torta da polpa da macaúba para caprinos, levando-se em conta, além do fator custo de produção, que a macaúba também é considerada uma espécie que se mantém produtiva sob condições restritivas à maioria das culturas.

\title{
Conclusão
}

A diversificação da composição da dieta de cabras em lactação, através da inclusão da torta da polpa de macaúba no concentrado, é uma alternativa viável tecnicamente para cabras no terço final de lactação, com potencial para reduzir os custos com a alimentação.

\section{Macaúba pulp cake on diet of dairy goats}

\begin{abstract}
In order to evaluate the technical and economic feasibility of including macaúba pulp cake on the diet of goats in the final third of lactation, 16 adult animals were separated into two collective pens containing eight animals each, one of them receiving concentrate containing $41.2 \mathrm{~g}^{\mathrm{kg}} \mathrm{kg}^{-1} \mathrm{of}$ macaúba cake. The addition of macaúba pulp cake to the concentrate
\end{abstract}


reduced the consumption of roughage without affecting the performance of the animals. Likewise, the protein, fat, lactose and total solids content in the milk were not affected. The feed cost was reduced with the inclusion of the cake in the diet. The inclusion of the macaúba pulp cake to the diet of goats in the final third of lactation is technically and economically feasible for the inclusion level evaluated.

Keywords: Acrocomiaaculeat, feed, goats, ruminants

\section{Referências bibliográficas}

ABDAlLA, A. L.; SILVA FILHO, J. C. D.; GODOI, A. R. D.; CARMO, C. D. A.; EDUARDO, J. L. D. P. Utilização de subprodutos da indústria de biodiesel na alimentação de ruminantes. Revista Brasileira de Zootecnia, v. 37, n. SPE, p. 260-268, 2008.

ALTINO, H. O.; COSTA, B. E.; DA CUNHA, R. N. Biosorption optimization of Ni (II) ions on Macauba (Acrocomia aculeata) oil extraction residue using fixed-bed column. Journal of environmental chemical engineering, v. 5, n. 5, p. 4895$4905,2017$.

AZEVEDO, R. A.; ALMEIDA RUFINO, L. M.; SANTOS, A. C. R.; SILVA, L. P.; BONFÁ, H. C.; DUARTE, E. R.; GERASEEV, L. C. Desempenho de cordeiros alimentados com inclusão de torta de macaúba na dieta. Pesquisa agropecuária brasileira, v. 47, n. 11, p. 1663-1668, 2012.

AZEVEDO, R.; RUFINO, L.; SANTOS, A.; JÚNIOR, R.; RODRIGUEZ, N.; GERASEEV, L. Comportamento ingestivo de cordeiros alimentados com torta de macaúba. Arquivo Brasileiro de Medicina Veterinária e Zootecnia, p. 490496, 2013.

AZEVEDO, R.A., BICALHO, F.L., ARAÚJO, L., RIBEIRO JR., C.S., SANTOS, A.C.R., JAYME, D.G., \& GERASEEV, L.C.. Análise técnico-econômica de diferentes níveis da torta de macaúba em dietas para vacas leiteiras.Arch. zootec., Córdoba , v. 62 , n. 237 , p. 147-150, 2013 . 
BAUMAN, D. Regulation of nutrient partitioning during lactation: homeostasis and homeorhesis revisited. Ruminant physiology: digestion, metabolism, growth and reproduction, p. 311-328, 2000.

CHILLIARD, Y. Dietary fat and adipose tissue metabolism in ruminants, pigs, and rodents: a review. Journal of Dairy Science, v. 76, n. 12, p. 3897-3931, 1993.

CHILLIARD, Y.; GLASSER, F.; FERLAY, A.; BERNARD, L.; ROUEL, J.; DOREAU, M. Diet, rumen biohydrogenation and nutritional quality of cow and goat milk fat. European Journal of Lipid Science and Technology, v. 109, n. 8, p. 828-855, 2007.

COLOMBO, C. A.; BERTON, L. H. C.; DIAZ, B. G.; FERRARI, R. A. Macauba: a promising tropical palm for the production of vegetable oil. OCL, 2017.

DETMANN, E.; SOUZA, M. D.; VALADARES FILHO, S. D. C.; QUEIROZ, A. D.; BERCHIELLI, T.; SALIBA, E. D. O.; CABRAL, L. D. S.; PINA, D. D. S.; LADEIRA, M.; AZEVEDO, J. Métodos para análise de alimentos. Visconde do Rio Branco, MG: Suprema, p. 214, 2012.

EVARISTO, A. B.; GOUlART, S. D. M.; MARTINS, A. D.; PIMENTE, L. D.; GROSSI, J. A. S. Caracterização físico-química de frutos de macaúba provenientes de três regiões do estado de Minas Gerais. Revista Agrotecnologia, v. 8, n. 2, p. 81-92, 2017.

GRANDE, S. C.; CREN, É. C. Demanda de proteínas vegetais: potencialidades e o diferencial dos farelos de macaúba (revisão). The Journal of Engineering and Exact Sciences, v. 2, n. 3, p. 190-214, 2016.

HENDERSON, A.; GALEANO-GARCES, G.; BERNAL, R. Field guide to the palms of the Americas. Princeton University Press, 1997. 
HOFMANN, R. R. Evolutionary steps of ecophysiological adaptation and diversification of ruminants: a comparative view of their digestive system. Oecologia, v. 78, n. 4, p. 443-457, 1989.

JENKINS, T. Fatty Acid Composition of Milk from Holstein Cows Fed Oleamide or Canola Oil1. Journal of dairy science, v. 81, n. 3, p. 794-800, 1998.

LOPES, F. B.; FERREIRA, J. L. SENSIBILIDADE ECONÔMICA DO SISTEMA INTENSIVO E SEMI-INTENSIVO DA PRODUÇÃO EM CAPRINOS LEITEIROS: BENEFÍCIOS DOS FATORES TANGÍVEIS E INTANGÍVEIS Economic sensitivity of intensive and semi-intensive dairy goats system: the benefits of tangibles and intangibles factors. Revista Acadêmica: Ciência Animal, v. 11, n. 4, p. 403-411, 2017.

MADUREIRA, K. M.; GOMES, V.; DE ARAÚJO, W. P. Características físicoquímicas e celulares do leite de cabras Saanen, Alpina e Toggenburg. Revista Brasileira de Ciência Veterinária, v. 24, n. 1, 2017.

MINISTÉRIO DA AGRICULTURA E DO ABASTECIMENTO. Secretaria Nacional de Defesa AgropecuáriaRegulamento Técnico de produção, identidade e qualidade do leite de cabra.Instrução Normativa $\mathbf{n}^{\circ} \mathbf{3 7}$ de 31 de outubro de 2000.

MORAND-FEHR, P.; FEDELE, V.; DECANDIA, M.; LE FRILEUX, Y. Influence of farming and feeding systems on composition and quality of goat and sheep milk. Small Ruminant Research, v. 68, n. 1, p. 20-34, 2007.

NATIONAL RESEARCH COUNCIL. COMMITTEE ON NUTRIENT REQUIREMENTS OF SMALL RUMINANTS et al. Nutrient requirements of small ruminants: sheep, goats, cervids, and new world camelids. 2007.

PALMQUIST, D.; JENKINS, T. Fat in Lactation Rations1, 2. Journal of dairy science, v. 63, n. 1, p. 1-14, 1980. 
PIRES, A. J. V.; JÚNIOR, J. N. D. C.; DA SILVA, F. F.; VELOSO, C. M.; DE SOUZA, A. L.; DE OLIVEIRA, T. N.; DOS SANTOS, C. L.; DE CARVALHO, G. G. P.; BERNARDINO, F. S. Farelo de cacau na alimentação de ovinos. Ceres, v. 51, n. $293,2015$.

PIRES, T. P.; DOS SANTOS SOUZA, E.; KUKI, K. N.; MOTOIKE, S. Y. Ecophysiological traits of the macaúba palm: a contribution towards the domestication of a novel oil crop. Industrial Crops and Products, v. 44, p. 200$210,2013$.

QUEIROGA, R.; FERNANDES, M.; MEDEIROS, A.; COSTA, R.; OLIVEIRA, C.; BOMFIM, M.; GUERRA, I. Physicochemical and sensory effects of cotton seed and sunflower oil supplementation on Moxotó goat milk. Small Ruminant Research, v. 82, n. 1, p. 58-61, 2009.

RENNÓ, F.P.; PEREIRA, J.C.; LEITE, C.A.M.; RODRIGUES, M.T.; CAMPOS, O.F.; FONSECA, D.M. e RENNÓ, N.N. Eficiência bioeconômica de estratégias de alimentação em sistemas de produção de leite: produção por animal e por área. Rev Bras Zootecnia, v. 37, p.743-753, 2008.

RATTER, J. A.; BRIDGEWATER, S.; RIBEIRO, J. F. Analysis of the floristic composition of the Brazilian cerrado vegetation III: comparison of the woody vegetation of 376 areas. Edinburgh journal of botany, v. 60, n. 01, p. 57-109, 2003.

RIGUEIRA, J. P. S.; MONÇÃO, F. P.; DE SALES, E. C. J.; DOS REIS, S. T.; ALVES, D. D.; DE AGUIAR, A. C. R.; JÚNIOR, V. R. R.; CHAMONE, J. A. Composição química e digestibilidade in vitro de tortas da macaúba. Unimontes Científica, v. 19, n. 2, p. 62-72, 2017.

RISCO, C.; MELENDEZ, P. Dairy production medicine. John Wiley \& Sons, 2011. 
SANTOS, A. C. R. D.; AZEVEDO, R. A. D.; JÚNIOR, V.; FERREIRA, G.; RODRIGUEZ, N. M.; DUARTE, E. R.; GERASEEV, L. C. Effects of macauba cake on profile of rumen protozoa of lambs. Revista Brasileira de Zootecnia, v. 46, n. 3, p. 251-256, 2017.

VASCONCELOS, V. R.; LEITE, E. R.; ROGÉRIO, M. C. P.; PIMENTEL, J. C. M.; NEIVA, J. N. M. Utilização de subprodutos da indústria frutífera na alimentação de caprinos e ovinos. Embrapa Caprinos e Ovinos-Documentos (INFOTECAE), 2002. 